Cahiers $d u$ MONDE RUSSE

\section{Cahiers du monde russe}

Russie - Empire russe - Union soviétique et États indépendants

$50 / 4 \mid 2009$

Varia

\title{
Malte Rolf, Sovetskie massovye prazdniki
}

\section{Alexandre Sumpf}

\section{OpenEdition \\ Journals}

Édition électronique

URL : https://journals.openedition.org/monderusse/7166

DOI : 10.4000/monderusse. 7166

ISSN : $1777-5388$

\section{Éditeur}

Éditions de l'EHESS

\section{Édition imprimée}

Date de publication : 15 décembre 2009

Pagination : 807-809

ISBN : 978-2-7132-2261-0

ISSN : $1252-6576$

\section{Référence électronique}

Alexandre Sumpf, «Malte Rolf, Sovetskie massovye prazdniki », Cahiers du monde russe [En ligne], 50/4 | 2009, mis en ligne le 12 janvier 2011, consulté le 03 septembre 2022. URL : http:// journals.openedition.org/monderusse/7166; DOI : https://doi.org/10.4000/monderusse.7166

Ce document a été généré automatiquement le 3 septembre 2022

Tous droits réservés 


\title{
Malte Rolf, Sovetskie massovye prazdniki
}

\author{
Alexandre Sumpf
}

\section{RÉFÉRENCE}

Malte RoLf, Sovetskie massovye prazdniki [Les fêtes de masse soviétiques]. Moscou : ROSSPEN, 2009, 440 p. (Traduction de : Das Sowjetische Massenfest, Hambourg : Hamburger Edition, 2006, 453 p.)

1 Dans cet ouvrage primé ${ }^{1}$, tiré d'une thèse non moins distinguée ${ }^{2}$, Malte Rolf situe son analyse du stalinisme à la croisée de la génétique des fêtes, de la symbolique du pouvoir, de l'histoire du quotidien et de la monographie régionale. Il comble une lacune importante, non seulement par sa démarche liant les discours à la pratique sur le terrain, mais par son ambition d'analyser le phénomène des fêtes officielles soviétiques dans le temps tout en variant les focales spatiales. Les allers-retours entre Moscou - à la fois centre programmateur et patron à imiter - et deux capitales régionales - Voronež et Novosibirsk, tout comme l'attention portée à l'héritage tsariste, aux phases de développement sur l'ensemble de la période soviétique, à l'imposition du modèle aux démocraties populaires ou à l'hybridation dans la Russie actuelle se révèlent dans l'ensemble convaincants.

2 La réflexion sans cesse reprise sur les sources et leurs limites, séduisante, débouche toutefois trop systématiquement sur un constat d'impuissance à atteindre une inaccessible "réalité». Outre l'oubli des lettres aux rédactions et des échos locaux ( $s$ mest) dans son appréhension trop globale de la presse régionale, l'auteur n'a, par exemple, pas dû assez bien regarder les images cinématographiques qu'il écarte (p. 245) sans même tenter de distinguer fiction, documentaire et actualités, sans interroger la notion (débattue) de « culture visuelle » soviétique ${ }^{3}$, ni prendre en compte la dimension technique de production, diffusion et réception de la fête par ce média spécifique. 
Cependant, Rolf démontre brillamment que la fête incarne plus qu'un type parmi d'autres de propagande. La "culture de la fête» soviétique est un médium de construction du nouvel ordre soviétique, un vecteur essentiel de la "soviétisation interne» des provinces. À travers le maquis de formules moins heuristiques que séductrices, l'ouvrage permet une réelle avancée de notre appréhension des rituels et des programmes festifs russo-soviétiques.

4 Une première partie fait d'abord le bilan des pratiques tsaristes, qui apportent la théâtralité à un calendrier festif structuré autour de la liturgie orthodoxe puis pris, avant-guerre, par la frénésie jubilaire. En ville s'opposent les narodnye gul'janija [kermesses], dont l'identité russe affirmée fait l'objet du partage populaire, et les fêtes ouvrières appartenant à un registre international(iste), marginales dans la société. Dans le fil des travaux de Figes et Kolonickij, Rolf considère que l'année 1917 a été marquée par l'inversion carnavalesque et l'émergence d'une "politique de la rue », peu analysée malheureusement, d'autant qu'il n'en est plus guère question ensuite.

Les trois parties suivantes, cœur plus fouillé de l'étude, sont consacrées aux années de façonnement du modèle de la fête soviétique (1917-1941) à travers sa planification, la mise en œuvre et en scène (notamment en province) du temps et de l'espace, la création d'un espace de médiation à double sens entre société et pouvoir. Rolf montre que l'Armée rouge a apporté avec elle ordre et calendrier soviétique, en ville en tout cas, tant les campagnes semblent peu affectées. Sous la NEP, des bolcheviks de premier rang (Lunačarskij, Krupskaja) et de niveau intermédiaire (Nikolaj Podvojskij) produisent un intense effort de théorisation et d'organisation des fêtes, censées allier activité spontanée (samodejatel'nost') et direction (rukovodstvo), participation populaire et programme éducatif, émotion partagée des manifestants et stigmatisation des ennemis exclus de la liesse. Le jubilé de 1927 précipite le passage à une planification systématique, au travers de commissions spécifiques où siège une couche de "spécialistes" autoproclamés - qui auraient pu faire l'objet d'une étude de cas ou d'une prosopographie. La deuxième partie traite des discours et de la planification des fêtes par le pouvoir central, ainsi que du transfert de ce modèle dans les provinces.

6 Les relations centre(s)/périphérie(s) forment le cœur de la troisième partie. La centralisation de la fête impose un modèle de déroulement - installation des décors, défilé et discours, divertissements - et organise la loyauté des provinces envers le centre, surtout pendant la Terreur. La presse joue un rôle éminent dans la préparation et la diffusion du patron, participant de la colonisation du temps par le nouveau calendrier, et inscrit dans la « carte mentale » des Soviétiques un espace redessiné par la toponymie, les nouvelles constructions et la maîtrise de l'urbanisation (une carte aurait été bienvenue ici). Le centre de Voronež est déplacé vers la nouvelle " ville socialiste ", on trouve enfin un centre et une orientation à la ville récente de Novosibirsk. Calqué sur la liturgie orthodoxe qu'il entend combattre, le calendrier soviétique ne parvient toutefois pas à trouver son rythme autonome, en dépit de la hiérarchisation des fêtes; la reprise d'une partie du rituel ecclésial ajoute à la confusion. La fête n'est pas "purement " soviétique en tant que telle, mais reflète et construit la nouvelle échelle sociale par la mise en scène, au cœur même de la fusion entre masse et dirigeants, d'une hiérarchie interne (variable) des manifestants, et d'une exclusion de hors-caste (lišency).

7 De fait, comme le montre la quatrième partie, la « culture de la fête » soviétique est à la fois réinterprétation d'une norme autoritaire et compromis. Son rituel hybride traditions et innovations, modèle culturel de la capitale politique et pratiques locales, 
démonstration des victoires du régime et soviétisation de la population. Malgré le défaut constant de moyens financiers et humains (qui aurait pu bénéficier d'une comparaison chiffrée), la «fiction » de la fête continue à se déployer même lors de la famine de 1932-1933 ou pendant la Grande Terreur, ne trouvant ses limites qu'au cours de la Seconde Guerre mondiale. C'est que, pendant les années 1930, la fête devient une "routine", une constante de l'espace social soviétique, quasi uniforme comme le suggèrent les cas provinciaux. La partie spectaculaire et divertissante y prend de plus en plus d'importance, symbolisée par les parades de culturistes.

En dépit des promesses du sommaire, les degrés d'acceptation, d'endurance, d'indifférence, de rejet ou d'opposition restent indéterminés. L'absentéisme aux défilés, fréquent et massif, est d'abord interprété par les autorités comme un défaut d'organisation, puis criminalisé. Une étude des « procès de camarades » dans les ateliers, entre les lignes des discours convenus de l'exercice, aurait peut-être éclairé le point de vue des indifférents et mis en évidence des catégories différentes d'hostilité. En revanche, le passage (p.224-233) sur l'utilisation des fêtes comme justification des demandes matérielles par les autorités et les usines, donc comme mode d'administration de la pénurie générale, fonctionne à merveille. Au village, estime aussi l'auteur à juste titre, les fêtes offrent surtout des dates butoirs pour les rapports et un rythme pour les campagnes qui se succèdent en permanence. Il n'y a pas de fête soviétique rurale, ni organisée "d'en haut » avec suffisamment de vigueur, ni réinterprétée « d'en bas » audelà du prétexte à l'habituelle ivresse collective.

9 La dernière partie, "Mise en contexte ", compare l'expérience soviétique avec les cas fasciste, national-socialiste et américain, puis retrace à grands traits l'évolution de la fête soviétique sous le stalinisme triomphant, la déstalinisation, la stagnation brejnévienne et après la chute de l'URSS. Les dictatures partagent leur inventivité en matière de fête, créant une " culture propre » qui sait assimiler les anciennes pratiques ; mais la fête soviétique est plus ferme dans son déroulement et ses principes, éducative avant d'être émotionnelle. Pour le compte des démocraties, l'exemple américain sert la comparaison dans le sens des disparités (pas de centralisme, de planification, caractère marginal de la fête dans la légitimation du pouvoir en place, qui passe par les élections), mais celui de la France aurait peut-être mieux interrogé le pacte entre citoyens et régime. La postérité du modèle d'avant-guerre en URSS trace des perspectives intéressantes sur l'incapacité à construire une mémoire collective de la Grande Guerre patriotique (débat autour de la fête de la victoire), la non-commémoration de la mort ou de la naissance de Stalin, et surtout le compromis brejnévien entre privatisation de la fête et acceptation superficielle de ses enjeux politiques par la population. De quoi, sans doute, rédiger un ouvrage aussi provocant, et peut-être plus solide dans son usage des sources, que celui-ci - dont la lecture, dans un russe clair, apparaît tout à fait recommandable. 


\section{NOTES}

1. Prix de traduction Geisteswissenschaften International

2. Prix Eberhard Karls (2004) de la meilleure thèse de l'université de Tübingen, et prix Klaus Mehnert (2005) de la Société allemande des études est-européennes.

3. Voir, par exemple, les travaux de Boris Groys ou d'Erika Wolf. 